DOI: 10.20472/IAC.2018.038.027

\author{
IOANA PALADE
}

Babes-Bolyai University, Romania

\title{
HEALTH PROFESSIONAL'S RETENTION IN RURAL AND REMOTE AREAS. A CASE STUDY ON RURAL AREAS OF BUCOVINA, ROMANIA
}

\begin{abstract}
:
The topic of this paper approaches a complex issue, namely the migration of medical professionals from rural areas. The Romanian medical system has its lacks, but the real problem is in rural and remote areas, where the working conditions determine the general practitioners' migration. In order to analyze this phenomenon and come up with some solutions, we developed a mixed-method study, having recourse to two research methods: the interview and the Discrete Choice Experiment. The Discrete Choice Experiment will focus on finding out the factors that drive the health professionals to migrate from rural and remote areas. Furthermore, the focus group completes our approach, outlining the health professionals' opinion with regards to the working conditions from rural areas of Bucovina. Also, after analyzing the results, we focus on finding some workforce retention strategies. Our findings suggest that the main factors which determine the migration of physicians are the quality of the facility, housing, length of commitment, study assistance, salary and management. These are the main areas that need improvement. Also, the results of the interviews revealed the fact that the family physicians from rural areas of Bucovina are not satisfied with their working conditions and their salaries.
\end{abstract}

\section{Keywords:}

health professionals, rural areas, migration, retention, workforce

JEL Classification: 118 